\title{
Constitutional Proportionality in the Post-Non-Classical Scientific Paradigm and Modern Practice
}

\author{
D. A. Pashentsev ${ }^{\#}$ \\ Institute of Legislation and Comparative Law of the Government of the Russian Federation, \\ Moscow, Russia \\ e-mail: dp-70@mail.ru
}

Received March 5, 2021; revised March 12, 2021; accepted April 12, 2021

\begin{abstract}
This article reveals the concept of proportionality in constitutional law based on the methodology of modern post-non-classical jurisprudence. Constitutional proportionality is considered in conjunction with constitutional identity and justice and is interpreted as a basis of legal co-evolution. It is noted that proportionality, imbued with moral content, presupposes finding a balance between universal principles and national values, collective and individual rights, and uniform constitutional standards and state sovereignty. With regard to constitutional law, the content of the proportionality principle is constitutional values in their practical implementation. At the same time, proportionality implies finding a balance between national and universal values as a condition for the harmonious development of the legal system. Universal values and foreign norms can gain the right to exist in the Russian legal system if they successfully pass the constitutional filter and will be recognized as not contradicting the Russian Constitution and its basic provisions. Therefore, it is necessary to develop an effective system for assessing foreign norms, decisions, and approaches, which will be based on the need to preserve national identity.
\end{abstract}

Keywords: constitutional proportionality, constitution, justice, constitutional identity, constitutional values, legal tradition.

DOI: $10.1134 / \mathrm{S} 1019331621030175$

\section{PROPORTIONALITY IN THE CONTEXT OF CONTEMPORARY GLOBAL CHALLENGES}

Large-scale changes that are taking place in public relations not only change the models of legal regulation, but also inevitably urge us to analyze and revise the concepts and theoretical and legal constructions already established. The situation of a phase transition, associated with a change in the technological paradigm and the model of social relations that it brings about, can not only change a number of basic parameters of existing law but also affect the very role of law in society. In these conditions, legal scholars are increasingly interested in the basic, pivotal concepts and principles that form the basis of legal regulation and determine the nature of law as a unique phenomenon.

The concept of proportionality has not received sufficient attention from domestic legal scholars. As a rule, it is used in civil law when it comes to liability for nonfulfillment of obligations, penalties, and the

\footnotetext{
\# Dmitrii Alekseevich Pashentsev, Dr. Sci. (Law), is a Professor and Head of the Department of the Theory of Law and Interdisciplinary Research of Legislation at the Institute of Legislation and Comparative Law at the Government of the Russian Federation.
}

amount of compensation [1]. However, today, proportionality can become one of the principles providing the basis for the development of public law, including constitutional law.

As one of the greatest jurists of the twentieth century, Hans Kelsen, believed it is the constitution that acts as the main rule that underlies the entire legal system, from which the rest of the rules that form the branches of law are logically derived [2]. Therefore, this principle founded on constitutional proportionality can be implemented successfully in other branches of law, acting as the basis of the modern legal order.

The challenges of the modern world lie in the mainstream of the dialectical contradiction between opposite tendencies gaining strength-globalization and regionalization, modernization and traditionalism, and universalism and preservation of national values.

The struggle of opposites is also characteristic of the development of law, in which the contradictions between public and private law regulation, imperative and dispositive methods, general principles and specific norms, and legislation and the practice of its enforcement are aggravated. Within the framework of these contradictions of a global nature, many narrower 
and particular issues appear, often of fundamental importance for the development of the domestic legal system. One of those is the issue of the relationship between constitutional identity and universal values, which today is assuming not only a legal, but also a political character. Addressing it is complicated by the lack of a unified doctrinal understanding of the essence and nature of constitutional values, as well as different approaches to formulating this concept, from purely legal principles to the inclusion in their composition of universal moral guidelines [3, p. 404].

The question of the relationship between the national and the universal in the culture and values of modern society goes far beyond the framework of constitutional law and the legal sphere in general. Its solution is determined by the geopolitical and socio-economic situation, the processes taking place in the world, and contemporary global challenges. It is on this issue that the state sovereignty of Russia, its understanding and practical implementation both within the country and in the international arena, largely depend. Realization of this truth has led to the fact that, among the amendments to the Constitution of the Russian Federation adopted in 2020, one of the central places is occupied by a change associated with the priority of the norms of the Russian Basic Law over rulings of international bodies. The inclusion in the Constitution of the norm that decisions of international bodies adopted on the basis of the provisions of international treaties signed by the Russian Federation in their interpretation, contrary to the Constitution of the Russian Federation, are not subject to execution in our country, is aimed at preserving and protecting constitutional identity. This norm establishes that the Constitution of Russia, as a sovereign state, is the basis of the national legal order, and even an international treaty cannot change the provisions of the Basic Law, which serves as the legal form of the independent historical development of the peoples of Russia. Taking into account the axiological content of the updated Constitution and its consistency with the historically established value standards in our country, the protection of constitutional norms becomes a factor in the preservation of national identity.

It seems logical to consider constitutional identity as the consistency of the principles and norms of the current Constitution in their practical implementation with national legal traditions and national legal values. This very approach is taken by the Chairman of the Constitutional Court of the Russian Federation V.D. Zorkin in interpreting constitutional identity when he notes that the problem of national identity arose in connection with the process of globalization. In his opinion, "the constitutional identity is crystallized by each state from its unique individual experience ... [and] is a set of beliefs and ideas from the historical past of each country, which are reinterpreted anew in each new era" [4, p. 12].
The constitutional identity is inextricably linked with the stability of the Basic Law, which means the preservation of basic constitutional principles and values [5]. It assumes particular importance in the conditions of modern society when, under the influence of digital technologies, the changes taking place in the world jeopardize even the identity of an individual person [6].

The challenges of digitalization are forcing states to respond by adopting new legal norms, tightening control, and strengthening the law enforcement system. The task of overcoming the growing intercommunal, interethnic, and interreligious confrontation, which has become a consequence of global turbulence and heterogeneity of social development, stimulates a greater regulation of people's lives than before, while new technologies provide the necessary means for this. This process, aimed at the formation of a tolerant and conflict-free society, leads to the replacement of national cultures with a single civilization, "the existence of individuals is replaced by the legal personality of citizens, which means the actual end of spiritual, actually intercultural relations" [7, p. 77]. An average increase in the rights and freedoms of an abstract citizen means a simultaneous reduction in the rights and freedoms of an individual concrete person, the horizon of possibilities of which is significantly limited.

The issue of the relationship between constitutional identity and universal values is in the focus of constitutional law but the grounds for its solution lie outside the designated framework. Moreover, these foundations have three basic components-philosophical and axiological, global outlook, and theoretical and legal. The analysis of the components in their practical aspect presupposes a meaningful answer to the question of how the principle of proportionality and its place in the system of principles of law are understood today, which, in turn, are transformed under the influence of a new reality corresponding to the postmodern society and postnonclassical scientific rationality. It is important to determine from what positions the meaning and ratio of universal and national values, their dynamics in conditions of global turbulence, and the clash of liberal and conservative tendencies are interpreted.

The issue of determining the criteria, based on which the limits of the interference of supranational structures in the development of the national political and legal system are established, is directly related to modern political and legal practice. It appears reasonable to agree that the desire to fulfill the international obligations of the state should not conflict with the sovereign will of the people, which is expressed in the norms of the constitution [8].

The issue of maintaining constitutional proportionality is inextricably linked with a number of contradictions generated by the multivector processes taking place in the modern world-globalization and 
regionalization, universal and traditional national values, and international and domestic law.

Among the above-mentioned contradictions, only the third is directly in the legal plane and can be resolved by legal means. At the same time, the directions and options for its solution are largely determined by factors outside the domain of law. The theory of law, as R. Posner rightly noted, has its boundaries, but issues related to legal theory can and should be addressed by going beyond these boundaries and by attracting funds and achievements of other spheres of scientific knowledge and life rationality [9]. The contradiction between national and international law should be resolved taking into account the diversity of both legal and political factors operative in this area. The need to take into account the political component in the issue of the relationship between international and national law is determined by the fact that any answer thereto leads not only to legal, but also to political consequences, and very serious ones. At the same time, one of the criteria for resolving it can be constitutional proportionality, understood in the context of the history and essence of constitutionalism.

\section{CONSTITUTIONALISM IN THE CONTEXT OF MODERN LEGAL SCIENCE}

The scientific search for answers to the challenges of modern reality lies in the plane of post-nonclassical scientific methodology, trenchant consideration of which can be found in works of Academician V.S. Stepin [10]. The scientific methodology of the post-nonclassical stage of development is based on new methodological principles of cognition, more adequate to the complex processes taking place in the world and successfully complementing the principles of classical science.

Post-nonclassical jurisprudence introduces into the knowledge of law subjective and irrational principles and elements of uncertainty and contextuality [11]. Modern legal science speaks about the constructed nature of legal reality: scholars believe that the legal environment is created by the daily actions of the person at law, which embodies legal norms [12, p. 105]. With this approach, the knowledge of law is inseparable from the knowledge of the person at law, his mentality, and social and other factors affecting him.

A major role in the construction of legal reality is played by factors such as the system of basic legal values established and supported by the state and society, the existing national legal tradition with its specific legal mechanisms, the national mentality, and the national legal conscience. These phenomena form the basis of constitutional identity. We should recall the inextricable link between the system of national values and the legal tradition, described far back by H.J. Berman. In his view, it is the process of conscious transfer of legal values and institutions from one generation to another that forms the legal tradition [13, p. 19]. Accordingly, the national constitutional tradition is formed on the basis of constitutional values, which must be consonant with the national mentality.

It is possible to set up a legal reality on the basis of alternative principles and universal values. But in this case, a contradiction inevitably arises between the universal and traditional characteristics of the law and universal and national values. This contradiction can be classified as dialectical, serving as a factor in the development of the legal system. Universal and national values are in a state of continuous interaction and mutual enrichment. At the same time, it should be taken into account that the values passed off as universal in the modern world are often not such and frequently reflect precisely the moral and legal imperatives of Western civilization. Their implementation on a global scale is sometimes associated with a consistent rejection of national and local interests, norms, and traditions, which does not always have a positive effect on social development.

The emergence of Russian constitutionalism resulted from a complex synthesis of foreign constitutional ideas with the national traditions of democracy. The principle of democracy accompanying "the Russian state from the very first steps of its independent existence historically was a priority because it relied on a kind of mechanism for building the state-with territorial land management, conciliar, and not based on individual vassalage as was the case in the feudal states of Western Europe" [14, p. 111]. Combining with the national traditions of conciliarity and the zemstvo (local territorial administration based on elected local assemblies) structure of the state, the ideas of constitutionalism assumed a positive vector of development. Incidentally, in the West, the ideology of constitutionalism initially had a destructive orientation. Its creation pursued a pronounced practical goal, the overthrow of the absolute monarchy in Western Europe and the elimination of British colonial rule in North America. Today, the universal values of constitutionalism in its liberal version in a number of cases can retain their destructive role, initiating the transformation of legal systems towards uniform standards that do not always correspond to national legal traditions and national legal consciousness. At the same time, Russian constitutionalism, while preserving the values and institutions inherent in Western constitutional and legal thought, gave them new impulses aimed at developing the achievements of democracy and human rights that were accumulated within the framework of world culture and became an important heritage of it.

The amendments made to the text of the Basic Law in 2020 reflected the modern experience of applying the Constitution and were aimed, among other things, at the further development of its value potential, the evolution of Russia as a social and rule-of-law state. 
The updated Constitution clearly consolidated axiological priorities such as support for family, motherhood, fatherhood, and childhood, protection of the institution of marriage as the union of a man and a woman, protection of citizens' dignity, and respect for the working man. Specific constitutional guarantees were provided for the implementation of the principle of the welfare state, which without this could not fully unlock its socio-forming potential. Thus, as a result of the 2020 constitutional reform, the value catalog of the Constitution has been significantly expanded, it reflects more fully the spiritual traditions and ideals of Russian society [3, p. 408].

The values enshrined in the text of the Constitution of the Russian Federation of 1993 and concretized by the amendments of 2020 are largely consistent with the national mentality of the peoples of Russia and their idea of justice, while contributing to strengthening the relationship between constitutional legislation and the spiritual culture of the society. This is an important factor in enhancing confidence in the government as the basis of its legitimacy. Legitimation in society "is formed in a natural way, by the population's acceptance of the innovation that is developed by the ruling elite and the reference group" [15, p. 9]. The inclusion in the text of the Constitution of specific guarantees for implementing norms that correspond to the values shared by the majority of society helps to increase the legitimacy of power as an important factor of state stability, and is also focused on achieving a higher level of constitutional proportionality.

The problem of trust, always existing in one way or another in the relationship between the state and society, is successfully solved through axiological innovations in constitutional law. Trust in society is transmitted through symbolic systems and institutions, among which a prominent place is occupied by legislation, which is a "symbolic system that generates trust" [16, p. 281]. However, it can only perform this function on one condition-legal norms must be substantially consistent with the idea shared by the country's population about justice, morality, and humanism; they must be in tune with the system of values inherent in the given society.

The system of values enshrined in the Russian Constitution acts as a solid foundation for the development of the country's legal system and can be considered as one of the filters through which all new borrowings of foreign law must pass. Gradually, it becomes axiomatic that no foreign legal institution that contradicts the norms or the spirit of the Russian Constitution can be implemented into the domestic legal system.

Large-scale adoption of foreign legal experience has always been characteristic of the Russian legal tradition. For example, in the Russian Empire the bill of exchange legislation was completely and literally borrowed (Bill of Exchange Charter, 1729). Earlier, bor- rowings were actively used when creating the Council Code of 1649. There are other, very numerous examples [17]. However, even recognizing the importance, and in some cases the usefulness of the adoption and implementation of certain institutions of foreign law as well as the norms of international law, it is necessary to take into account possible contradictions between their axiological content and domestic legal values.

We should not forget that many of the values that are presented today as universal were not originally perceived as such. Like any social and legal construct, they arose as a result of initial arbitrariness, which then, as a result of social amnesia, was taken to be a consequence of natural development [18]. Most of the values in law, which today are called universal, originally had the same particular character as traditional values, which the supporters of universalism declare obsolete and are not adequate to the current stage of world development. Ultimately, all values are controversial; they inevitably give rise to a conflict of interpretations [19, p. 17].

Not too long ago, it seemed that the development of the modern world was entirely determined by the process of globalization, which has given rise to the tendency to universalize law on the basis of universalism of values. Today, the opposite trend has also emerged: along with globalization, the process of regionalization is intensifying, which is associated with the promotion and upholding of traditional values that determine the originality of each national legal system. In the context of the coronavirus pandemic, the world has shown a desire for self-absorption, geographic isolation, and abandonment of a number of seemingly unshakable liberal freedoms. This exacerbates the question of the search for proportionality in constitutional law, which develops, on the one hand, on the basis of the existing constitutional and legal tradition, and on the other hand, under the pressure of universal values that directly affect the rulings of international courts.

On addressing the issue of constitutional proportionality, it should be borne in mind that, in the context of digitalization, there is a tendency for the evolution of the structural and substantive characteristics of the constitution. The activity performed by subjects for the implementation of legal norms takes place in a multidimensional social space, which is designed "according to the principles of differentiation and distribution, formed by a set of effective properties in the social universe considered" [20, p. 15]. The multidimensionality of social space in a digital society is multiplied by its multilayered nature and exponentially increasing multitasking of social interactions. The fourth industrial revolution "leads to the fusion of technologies and the blurring of the lines between the physical, digital, and biological spheres" [8, p. 66]. Such processes taking place in the emerging digital society require more flexibility from the Basic Law, 
the ability to respond in a timely manner and adequately to the rapidly changing and increasingly complex structure of social relations. There are forecasts predicting the emergence in the digital environment of an up-to-date version of the constitution, built on the principle of a knowledge base with the preservation of the basic core in the form of a direct constitutional text as the legal regulatory framework of public relations. Such a version, in addition to the text of the Basic Law itself, may include interpretations made by the Constitutional Court, which are contained in its decisions and definitions, doctrinal positions of scientists, generally recognized principles and norms of international law, and legal interpretations of international bodies and organizations [21]. All this expands the action space of the constitutional proportionality principle and increases its significance.

Improving legal guarantees for the implementation of constitutional norms in the context of digitalization seems to be an important step on the path of coevolution, which makes it possible to preserve national legal identity despite the existing risk of a convergent merger of nations and legal systems into a single digital-centric techno. Coevolution means the irreducibility of many national legal traditions to one common denominator, unification in diversity. The idea of coevolution assumes the joint development of systems while maintaining their qualitative uniqueness [7, p. 31], which also applies to legal systems.

Digitalization, as one of the processes dominant in terms of influence on the development of society, has another facet, which is important for the issue under consideration. The development digital society may involve the emergence of groups of social relations that cannot be effectively regulated only within the framework of national legislation. Consequently, the role of international legal regulators inevitably increases, which contradicts a number of trends in world development. This fact further exacerbates the need to search for proportionality between national and international law.

\section{CONTEXTUALITY OF PROPORTIONALITY}

Proportion is inextricably linked with justice and is its manifestation in law. The relationship between proportionality and justice is expressed through identity, which plays an important role in establishing the legitimacy of legal norms and institutions.

Justice as a legal phenomenon in its classical understanding actually represents the correspondence between action and retribution, work and remuneration, and guilt and responsibility [22, p. 68]. Under this approach, such correspondence underlying justice acts as the basis for proportionality.

Like justice, proportionality is contextual and its criteria and boundaries are flexible. In fact, in the field of law, problems are constantly being solved related to the establishment of proportionality in specific cases. The court acts as a significant institution that allows solving these problems and seeking proportionality as a necessary balance in each specific case. In conditions of the increasing complexity of social relations and the previously unprecedented multivector character of their development, the role of the judiciary naturally increases. In a number of cases, it is in a court decision that the balance of the proper and the existent is contained, which constitutes the legal content of proportionality.

Proportionality is a general legal principle and in this capacity is manifested in all branches of law. For example, it is of great importance in the sentencing of criminal offenses, where the punishment must be proportionate to the act committed. In history, this was clearly reflected in the laws of the Babylonian king Hammurabi, in which punishment was established according to the principle of retaliation (lex talionis) an eye for an eye and a tooth for a tooth. In civil law, proportionality is important, for example, when determining the amount of a penalty. In international law, proportionality is considered when dealing with reprisals and retortion. In fact, in all of these cases, the question of proportionality arises when it comes to certain sanctions. In constitutional law, this concept is often used in connection with the problem of limiting the constitutional rights of citizens, for example, electoral ones.

In general, it can be said that proportionality plays a different role in public and private law. While in private law the task of the proportionality principle is to ensure a balance of interests in the social space and the realization of subjective rights, in public law, the main goal of achieving proportionality is much more sublime and consists in protecting the foundations of the constitutional order and state sovereignty, preserving constitutional identity.

In the Western legal order, a certain algorithm has already been developed that allows courts, primarily constitutional ones, to apply the principle of proportionality when rendering judicial decisions. But analysis of this algorithm shows that its use actually replaces proportionality with ratability, and this is far from the same thing. Ratability is mainly related to quantitative characteristics that are quite applicable for calculating, say, the required compensation in the event of harm. Proportionality, in contrast to ratability, also includes an axiological component; therefore, its application in law depends on the value system on which the law enforcement officer relies.

\section{CONSTITUTION AS A CRITERION OF PROPORTION IN LAW}

It seems that the key to answering the above questions related to determining the relationship between universal values and national legal identity is the 
understanding of the proportionality principle, which, in turn, goes back to the philosophical category of "measure."

The category "measure" was one of the main ones among the ancient Greek philosophers, starting with Aristotle. Aristotle wrote that "in all cases, the measure and the beginning is something single and indivisible" [23, p. 254]. This idea was developed by Hegel, who believed that a measure is a qualitatively defined quantity [24]. It seems that, in relation to the law of a qualitative component of a measure, its substantive criterion is legal values, which in different cases and different legal traditions can differ significantly.

Measure is the unity of quantity and quality, that is the initial beginning, where quantitative and qualitative characteristics merge into a single whole. With regard to the Russian legal system, the Constitution acts as such an initial principle, uniting the quantitative and qualitative characteristics of law. It is the Constitution that can be considered as a criterion by which the principle of proportionality can be defined and implemented.

Proportionality in constitutional law presupposes finding a balance between universal principles and national values, between collective rights and individual rights, and between uniform constitutional standards and state sovereignty. It is provided with moral content since a human being is inseparable from moral principles. In relation to constitutional law, the content of the proportionality principle is constitutional values in their practical implementation. The implementation of the principles and norms of the constitution is carried out by legal subjects who bring the peculiarities of national legal consciousness into this process.

At one time, F. Lassalle said that there was a legal constitution-a set of formally adopted norms-and an actual constitution-the foundations of the constitutional order that existed in real life [25]. It appears that the national constitutional identity can manifest itself not only in the legal but also in the actual constitution, which includes, along with the written norms, the practice of their application, a number of customs, as well as the official interpretation given to these norms by the Constitutional Court. When we talk about constitutional identity, it is necessary to take into account both the legal and the actual constitution. The analysis of each of them will help to formulate and substantiate the concept of proportionality in relation to a specific legal situation.

The understanding of constitutional proportionality presented assumes that the borrowing of foreign legal experience and the recognition of supranational court decisions should be carried out taking into account the values of the national Constitution. Foreign norms can gain the right to exist in the Russian legal system if they successfully pass the constitutional filter and are recognized as not contradicting the Rus- sian Constitution and the basic democratic values and fundamental human rights that form its basis. Therefore, it is necessary to develop an effective system for assessing foreign norms, decisions, and principles, which will be based on the need to preserve national identity, including legal, taking into account the principle of justice and the values inherent in the domestic cultural tradition. An important role in such a system is to be played by the Constitutional Court, which can help to preserve the constitutional identity and to identify and implement the principle of constitutional proportionality in each specific case.

If the interpretations of the Constitutional Court are based on the domestic constitutional and legal doctrine, they will become an important factor in the subsequent practical implementation of the norms of the Russian Constitution and will serve as the basis for preserving the national legal tradition and constitutional identity as its basis. At the same time, not a single Russian judicial body should make decisions solely on the basis of quantitative indicators, without using value guidelines in its activity. The necessary conditions for the use of such guidelines, which have both legal and moral content, exist today.

After the 2020 constitutional reform, all decisions of international courts and the provisions of all international treaties signed by the Russian Federation must pass the proportionality test. In general terms, it assumes answers to a number of questions of a fundamental nature. It is necessary to determine to what extent the proposed innovations really have a universal character, to what extent they correspond to national legal traditions and established Russian values and to the spirit and content of the Constitution of the Russian Federation.

The answer to these difficult questions is impossible without relying on legal doctrine. It is scientists who using modern scientific methodology can reveal the criteria of the universal in law, identify the value content of the national legal tradition and its relationship with the spirit of the Constitution, and formulate criteria for constitutional proportionality.

Thus, the question about the content of constitutional proportionality and the search for its optimal forms assumes special significance in conditions when humanity is on the verge of a new era. The transitional period entails the exacerbation of existing and the emergence of new contradictions of both ontological and axiological nature. The development trends of the globalizing world lead to the unification of the world perception and the formation of standard, impersonal ideals and the corresponding patterns of behavior. At the same time, the imposition of new, historically and mentally alien behavioral patterns triggers destructive processes in the national culture and comes into conflict with the existing legal tradition. The negative impact that a person experiences as a central, key element of the legal system negatively affects the entire 
system and, as a result, the state. The protective mechanism making it possible to preserve the value-based core of the national legal tradition and political and legal culture provides for the actualization of the constitutional proportionality principle in its modern sense. Constitutional proportionality presupposes the use of the principle of justice, which, in turn, is impossible without relying on the system of values genetically inherent in the multinational people of Russia. Only in this case will constitutional proportionality become the basis of legal coevolution as a complex interaction and functional unity of all structural parts of the legal system in the face of modern global challenges.

\section{REFERENCES}

1. S. L. Degtyarev, "Application of the principles of fairness and proportionality of liability in compensation for losses," Arbitrazh. Grazhdan. Prots., No. 12, 56-57 (2018).

2. H. Kelsen, Reine Rechtslehre, 2nd ed. (Vienna, 1960).

3. T. Ya. Khabrieva, "Constitutional reform in Russia: Searching for national identity," Herald Russ. Acad. Sci. 90 (3), 273-282 (2020).

4. V. D. Zor'kin, "Civilization of law: Modern context," Zh. Konstituts. Pravosud., No. 5, 12 (2014).

5. T. Ya. Khabrieva, Constitutional Reform in the Modern World (Nauka RAN, Moscow, 2016) [in Russian].

6. V. A. Emelin, Identity in the Information Society (Kanon+, Moscow, 2017) [in Russian].

7. V. A. Kutyrev, V. V. Slyusarev, and T. M. Khusyainov, Humanity and Technos: A Philosophy of Coevolution (Aleteiya, St. Petersburg, 2020) [in Russian].

8. S. A. Gracheva, "Development of the concept of constitutional identity in connection with the search for approaches to resolving conventional-constitutional collisions and conflicts," Zh. Ross. Prava, No. 9, 52-64 (2018).

9. R. A. Posner, Frontiers of Legal Theory (Harvard Univ. Press, Cambridge, Mass., 2001).

10. V. S. Stepin, Theoretical Knowledge (Progress-Traditsiya, Moscow, 2003) [in Russian].
11. Postclassical Ontology of Law, Ed. By I. L. Chestnov (Aleteiya, St. Petersburg, 2016) [in Russian].

12. I. L. Chestnov, Postclassical Theory of Law (Alef-Press, St. Petersburg, 2012) [in Russian].

13. H. J. Berman, Law and Revolution: The Formation of the Western Legal Tradition (Harvard Univ. Press, Cambridge, Mass., 1983).

14. V. N. Sinyukov, Russian Legal System: Introduction to General Theory, 2nd ed. (Norma, Moscow, 2010) [in Russian].

15. I. L. Chestnov, "The problem of trust as a principle of civil society and law," Grazhdan. Obshch. Ross. Za Rubezh., No. 1, 7-10 (2011).

16. G. Hosking, Trust: A History (Oxford Univ. Press, Oxford, 2014).

17. D. A. Pashentsev, "Russian legislative tradition: Ontology of the process," Zh. Ross. Prava, No. 8, 5-13 (2018).

18. P. Bourdieu, "For rationalistic historicism," Tr. from Fr. by N. A. Shmatko, in Socio-Logos of Postmodernism: Almanac of the Russian-French Center for Sociological Research (Izd. Inst. Eksp. Sotsiol, Moscow, 1996), pp. 9-29 [in Russian].

19. Yu. Yu. Vetyutnev, Axiology of Legal Form (Yurlitinform, Moscow, 2013) [in Russian].

20. P. Bourdieu, Sociology of the Social Space, Tr. from Fr. and Ed. by N. A. Shmatko (Aleteiya, St. Petersburg, 2017) [in Russian].

21. T. Ya. Khabriaeva, Interpretation of the Constitution of the Russian Federation: Theory and Practice (Yurist, Moscow, 1998) [in Russian].

22. V. D. Zor'kin, "Justice is an imperative of a civilization of law," Teor. Gos. Prava, No. 2, 67-80 (2018).

23. Aristotle, Metaphysics: Works, in 4 vols., (Mysl', Moscow, 1975), Vol. 1 [in Russian].

24. G. Hegel, Science of Logic (Nauka, St. Petersburg, 1997) [in Russian].

25. F. Lassalle, On the Essence of the Constitution: A Speech Delivered in a Berlin Verein, Tr. from German by K. Chekerul'-Kusha (Burevestnik, Odessa, 1905) [in Russian].

Translated by I. Pertsovskaya 